\title{
Laclau y Žižek en sus laberintos: entre la herencia marxista y el posmarxismo
}

\author{
Fiorella P. Russo*
}

Fecha de Recepción: 1 de junio de 2021

Fecha de Aceptación: 30 de agosto de 2021

DOI: https://doi.org/10.46553/RGES.57.2021.p.281-301

\begin{abstract}
Resumen
Bajo el convencimiento de que las teorías contienden en un campo de lucha en el que confrontan unas con otras, este trabajo pone el foco en los posicionamientos de los que parten y de los que se desmarcan Ernesto Laclau y Slavoj Žižek a la hora de construir sus dispositivos teórico-políticos. En este camino, los autores corroboran una hoja de ruta inversa, puesto que mientras Laclau parte de la historia intelectual del marxismo, abandona sus categorías troncales y propone, en cambio, un posmarxismo; Žižek, desde un hegelianismo lacaniano y la crítica al posmodernismo, repone aquellos conceptos desdeñados por el posmarxismo laclausiano pero señeros del marxismo clásico.
\end{abstract}

Palabras clave: nuevos pensamientos críticos, teoría marxista, posmarxismo

\begin{abstract}
Under the conviction that theories contend in a field of struggle in which they confront each other, this work focuses on the positions of those who start and from which Ernesto Laclau and Slavoj Žižek stand out when building their theoretical-political devices. Along this path, the authors corroborate an inverse roadmap, since while Laclau starts from the intellectual history of Marxism, he abandons his core categories and proposes, instead, a post-Marxism; Žižek, from a Lacanian Hegelianism and a critique of postmodernism, replaces those concepts neglected by Laclausian post-Marxism but emblematic of classical Marxism.
\end{abstract}

Key words: new critical thoughts, Marxist theory, post-Marxism

\section{Introducción}

Las nuevas teorías críticas de la sociedad, como las denominó con intenciones de cartógrafo Keucheyan, ${ }^{1}$ constituyen una constelación de teorías que, más cerca o más lejos de la teoría marxista clásica, intenta renovar la crítica social y apostar por el potencial de la práctica política en las condiciones del capitalismo contemporáneo. Tal como lo explica el sociólogo sueco, tras la famosa crisis del marxismo, detonada en la década del setenta, los pensamientos de la crítica se encontraron ante el dilema de abandonar el marxismo como campo teórico (dadas las continuas derrotas sufridas tanto a nivel teórico como político) o de,

\footnotetext{
*IMESC-IDEHESI-CONICET. Correo electrónico: fioremes@gmail.com

${ }^{1}$ Keucheyan, R. Hemisferio izquierda. Un mapa de los nuevos pensamientos críticos (Madrid: Siglo XXI, 2013)
} 
al menos, revisitarlo de manera crítica en busca de sus potencialidades para pensar la política en los avatares actuales. En este campo de batalla podemos posicionar los dispositivos teóricos de Ernesto Laclau y de Slavoj Žižek.

Si bien ambos encuentran como punto en común la crítica de las condiciones de dominación del capitalismo contemporáneo y la búsqueda de nuevas conceptualizaciones en torno al sujeto de la emancipación, también se destacan por sus fuertes contrapuntos y por sus líneas de discrepancia. Aunque muchos son los ejes problemáticos ${ }^{2}$ mediante los cuales se pueden trazar líneas de combate entre ambos, en este trabajo el foco está puesto en los posicionamientos de los que parten y de los que se desmarcan para definir el horizonte de sus teorías políticas.

Así, el argumento que sostenemos es que para perfilar sus dispositivos teóricopolíticos ambos se posicionan en distintos puntos de largada y arriban a la línea de llegada por un camino inversamente proporcional: mientras que Laclau parte de la historia intelectual del marxismo y propone superarlo por sus debilidades para pensar la política contemporánea, Žižek aborda una teoría política basada en un hegelianismo-lacaniano que termina por reponer muchas de las categorías troncales del marxismo clásico. Dicho más claramente, lo que pretende este trabajo es indagar, en oposición, desde qué enfoques definen sus propuestas teórico-políticas estos autores y qué teorías o corrientes consideran que deben dejarse de lado para avanzar en pos de una salida a la encrucijada en la que se encuentra el pensamiento crítico contemporáneo.

\section{El Marx escindido de Laclau y su apuesta posmarxista}

"El marxismo se ha desintegrado y creo que me estoy quedando con sus mejores fragmentos"3

"Nuestro libro presenta la historia del marxismo [...] como un esfuerzo sostenido por escapar a la lógica [...] del determinismo"4

\footnotetext{
${ }^{2}$ Con ejes problemáticos nos referimos a la metodología de abordaje para los estudios en teoría social propuesta por Bialakowsky $(2014,2017)$ que implica el análisis sistemático del corpus textual a partir de un problema. Fue tomando este modo de abordaje que se constituyeron los resultados de esta pesquisa.

${ }^{3}$ Laclau, E. Nuevas Reflexiones sobre la revolución de nuestro tiempo (Buenos Aires: Nueva Visión, 2000), p 211.

${ }^{4}$ Laclau, E. y Mouffe, C. "Posmarxismo sin pedido de disculpas" En Laclau, E. Nuevas Reflexiones sobre la revolución de nuestro tiempo (Buenos Aires: Nueva Visión, 2000) p. 132.
} 
Podríamos afirmar que uno de los puntos de partida centrales de la empresa laclausiana es la negación de la equivalencia entre contradicción y antagonismo. El argentino parte de la hipótesis de lectura de que existe en el dispositivo teórico marxiano (y en la historia intelectual del marxismo, como veremos más adelante) un dualismo teórico entre una posición idealista y una materialista. En este sentido, el argentino desarrolla un análisis en el que señala que coexisten en Marx dos tendencias antagónicas. ${ }^{5}$ Por un lado, en el fragmento del Prólogo a la Contribución a la crítica de la economía política de 1859, Marx sostiene que el germen de autodestrucción del capitalismo es la contradicción entre las fuerzas productivas y las relaciones de producción:

En un estadio determinado de su desarrollo, las fuerzas productivas materiales de la sociedad entran en contradicción con las relaciones de producción existentes o - lo cual sólo constituye una expresión jurídica de lo mismo- con las relaciones de producción dentro de las cuales se habían estado moviendo hasta ese momento. Esas relaciones se transforman de formas de desarrollo de las fuerzas productivas en ataduras de las mismas. Se inicia entonces una época de revolución social. ${ }^{6}$

Por el otro lado, Laclau retoma el famoso segmento del Manifiesto Comunista en el que se pregona que el motor de la historia es la lucha de clases:

La historia de todas las sociedades hasta nuestros días es la historia de las luchas de clases. Hombres libres y esclavos, patricios y plebeyos, señores y siervos, maestros y oficiales, en una palabra: opresores y oprimidos se enfrentaron siempre, mantuvieron una lucha constante, velada unas veces y otras franca y abierta; lucha que terminó siempre con la transformación revolucionaria de toda la sociedad o el hundimiento de las clases en pugna. ${ }^{7}$

Sin embargo, según sostiene, hay aquí un problema. En el primer fragmento, Marx presenta una contradicción sin antagonismo, es decir, las fuerzas productivas, en un cierto punto, chocan con las relaciones de producción y esto produce el colapso mecánico del sistema capitalista. No obstante, nos dice, de esta contradicción que conduciría al inminente colapso no se sigue necesariamente que éste deba adoptar la forma de un enfrentamiento entre grupos y, menos aún, de clases. ${ }^{8}$ En el segundo pasaje, continúa, aparece un antagonismo sin contradicción, puesto que se presupone el carácter antagónico de las relaciones sociales, pero éste no se integra lógicamente en ningún momento con el modelo de cambio histórico de

\footnotetext{
${ }^{5}$ Laclau, E. y Mouffe, C., Hegemonía y Estrategia Socialista. Hacia una radicalización de la democracia. (Madrid: Siglo XXI, 1987); Laclau, E, Nuevas reflexiones...

${ }^{6}$ Marx, K., Contribución a la crítica de la economía política (México: Siglo XXI editores, 2008), p. 5.

${ }^{7}$ Marx, K. y Engels, F., El manifiesto comunista (México: Centro de Estudios socialistas Carlos Marx, 2011), p. 30 .

${ }^{8}$ Laclau, E, Nuevas reflexiones...
} 
contradicción entre las fuerzas productivas y las relaciones de producción que había planteado en el primer pasaje. La conclusión que saca Laclau de todo esto es que hay que deconstruir la afirmación por la cual la lucha de clases sería el resultado del despliegue necesario de las contradicciones en el ámbito de la economía. Para él, no tiene ningún sentido reducir el antagonismo a un momento interno del despliegue de la contradicción.

Pero volvamos a la dualidad presente en Marx. Como decíamos, para Laclau, la indefinición entre antagonismo y contradicción presente en el corpus teórico del pensador alemán se inscribe en una lucha entre dos posiciones epistemológicas o filosóficas antagónicas. Por un lado, hay una apuesta por la negatividad y la opacidad de lo social, que daría cuenta de una posible filosofía relacionista y no fundacionalista en Marx. Sin embargo, por el otro lado, hay también una cauterización de esa apuesta que se refleja en la propuesta normativa de Marx. Esto es, en la fe en una posible sociedad transparente y homogénea, en una sociedad comunista en la que no existirían las clases, en donde desaparecerían las relaciones de poder y en la que se lograría una emancipación acabada de la humanidad ${ }^{9}$. Así, su hipótesis central es que en la obra de Marx puede vislumbrarse una intención de ligar su materialismo a un relacionismo radical pero este movimiento es débil y no logra trascender los límites del autodespliegue del concepto.

Más aún, para Laclau la ambigüedad que existe en Marx se remonta al mismísimo Hegel, puesto que, por un lado, en la apuesta hegeliana la negatividad es un elemento constitutivo de toda identidad. Pero, por el otro, este movimiento de lo negativo no implica ninguna contingencia dado que se alcanza la identidad final en el momento de la síntesis. ${ }^{10}$ Esta interpretación de la dialéctica hegeliana es confrontada por Žižek, quien revisita una exégesis diferente de la misma. Para el esloveno, no hay autodespliegue del concepto, sino que la contingencia se cancela a sí misma y se convierte retroactivamente en necesidad. Es decir, a través de la repetición histórica, la contingencia es transubstanciada en la expresión de una necesidad. ${ }^{11}$

Volviendo a Laclau, para éste, la ambigüedad hegeliana se traslada a la problemática marxista ya que allí la negatividad y la opacidad no son constitutivas de lo social, sino que formarían parte de una prehistoria humana que sería posible trascender al arribar a una

\footnotetext{
${ }^{9}$ Para apoyar esta idea, en Nuevas reflexiones para la revolución de nuestro tiempo, Laclau se dedica a argumentar las profundas raíces milenaristas que existirían en la propuesta emancipatoria de Marx y de gran parte del marxismo (ver Laclau, E, Nuevas reflexiones..., p. 90, 91, 92, 95).

${ }^{10}$ Laclau, E, Nuevas reflexiones..., p. 215.

11 Žižek, S. "Da Capo senza Fine". En: Butler, J., Laclau, E. y Žižek, S., Contingencia, hegemonía, universalidad. Diálogos contemporáneos de izquierda (Buenos Aires: FCE, 2004), pp. 215-262.
} 
sociedad trasparente y homogénea. ${ }^{12}$ En este sentido, para él, el radical relacionismo de Marx es traducido inmediatamente a términos idealistas cuando propugna que el ser social es el que determina la consciencia (tesis que dio lugar, como sabemos, a las concepciones más deterministas de la ideología) y que la anatomía de la sociedad civil es la economía política, lo que significa que hay una lógica específica (la del desarrollo de las fuerzas productivas) que fundamenta el devenir histórico. ${ }^{13}$ Así, para el pensador argentino, Marx constituye un momento de transición, puesto que si bien, por un lado, mostró que el sentido de toda realidad humana se deriva de un mundo de relaciones sociales, terminó por concebir esta lógica relacional en términos esencialistas.

Asimismo, para él, la explicación marxista de la realidad social a partir del desarrollo de las fuerzas productivas es una historia sin exterior. Es por esto que tuvo que meter de contrabando a la lucha de clases, un suplemento que no se integraba fácilmente a sus categorías. Este elemento no es otra cosa que el de negatividad y antagonismo que Laclau pretende recuperar con su postulación posmarxista. Así, el argentino insiste en que hay una contradicción aquí pues: "Si la historia es un proceso objetivo, la negatividad no puede ocupar ningún papel en ella; por otra parte, sin negatividad no hay ni teoría ni acción revolucionarias". ${ }^{14} \mathrm{Y}$ lo que ha pasado en la historia del marxismo, nos dice, es que ese elemento supletorio que no podía ser integrado ha ido erosionando, poco a poco, el objetivismo originario de esta corriente.

Ahora bien, según el pensador argentino, la dualidad presente en Marx sigue apareciendo, como un síntoma, en las producciones posteriores que se desarrollaron en nombre del pensador alemán. Según señala, siempre que las visiones hegelianas y marxistas de la historia se han abierto a una priorización del papel de la lucha y la negatividad en la constitución de lo social, rápidamente han retrocedido hacia una teoría de la positividad de lo social, que Heidegger y Derrida han denominado "metafísica de la presencia" ${ }^{15}$ Lo que él intenta demostrar es que el carácter constitutivo de lo negativo trabaja, permanentemente, dentro de la teoría marxista desarticulando la pretendida coherencia de sus categorías cardinales. Según nos dice, la historia intelectual del marxismo es, justamente, la historia de la

\footnotetext{
${ }^{12}$ Laclau, E, Nuevas reflexiones...

${ }^{13}$ Laclau y Mouffe, Posmarxismo sin pedido...

${ }^{14}$ Laclau, E, Nuevas reflexiones..., p. 191.

${ }^{15}$ Laclau, E, Nuevas reflexiones...
} 
tensión permanente entre negatividad y positividad de lo social o, dicho de otro modo, entre idealismo y un materialismo bien entendido. ${ }^{16}$

Sin embargo, concede que si bien entre los teóricos de la Segunda Internacional domina el determinismo de clase, ha habido otros intelectuales que han intentado incorporar lógicas hegemónico-articulatorias retrayendo, así, el campo de la "necesidad histórica" de la teoría marxista. ${ }^{17}$ Estos serían los casos de Rosa Luxemburgo con su lógica del espontaneísmo, de Trotsky con su concepto de desarrollo desigual y combinado, y de Gramsci con su aparato teórico basado en los conceptos de hegemonía, bloque histórico y voluntad colectiva. Se trata, para Laclau, de autores marxistas que dieron un paso decisivo en una dirección materialista pero cuyos intentos fueron finalmente dominados por la concepción determinista de lo social.

Así pues, el argumento laclausiano respecto de la historia del marxismo puede resumirse de la siguiente manera: la Segunda Internacional fundó su estrategia política en una creciente centralidad de la clase obrera que iba ser el resultado de la simplificación de la estructura social bajo el capitalismo. Sin embargo, esta predicción no se cumplió en la realidad, sino que las dislocaciones propias del desarrollo desigual y combinado obligaron a la clase obrera a tomar tareas democráticas que no le hubiesen correspondido según las leyes del desarrollo histórico. En este contexto es que la socialdemocracia rusa diseñó el concepto de hegemonía para resolver esta asincronía de etapas. Sin embargo, no fue hasta Gramsci que el concepto leninista de alianza de clases se amplió hacia el de dirección moral e intelectual, al punto de que, para Gramsci, los agentes sociales no son clases, sino voluntades colectivas. ${ }^{18}$ Así, desde la perspectiva de Laclau, el revolucionario italiano fue el que permitió un pasaje de las formas esencialistas extremas de la Segunda Internacional a una concepción de las prácticas sociales como hegemónicas y articulatorias, lógica que, para él, es completamente compatible con el campo de los "juegos del lenguaje" de Wittgenstein y con la "lógica del significante" de Lacan. ${ }^{19}$

\footnotetext{
${ }^{16}$ Con esta expresión nos referimos a que, según Laclau, el materialismo de Marx permanece dentro del campo del idealismo puesto que la conocida inversión de la dialéctica hegeliana continúa sosteniendo, desde su perspectiva, la racionalidad de lo real al afirmar que existe una ley de movimiento que subyace a la historia y que puede ser conceptualmente aprehendida. Al contrario de esto, un "materialismo bien entendido" sería, para el argentino, aquel que no intente agotar la realidad del objeto, es decir, que no apele a la metafísica de la presencia. Según nos dice: "Todo esencialismo, por subordinar lo real al concepto, es idealismo, y [...] materialismo [...] una categoría que engloba a los varios intentos de romper con esta subordinación" (Laclau, [1990] 2000, p. 125).

${ }^{17}$ Laclau, E, Nuevas reflexiones...

${ }^{18}$ Laclau y Mouffe, Hegemonia y Estrategia Socialista...

${ }^{19}$ Laclau, E, Nuevas reflexiones...
} 
En este sentido, el eje del argumento de Laclau es que al tiempo que el esencialismo se iba desintegrando dentro del marxismo clásico, surgían nuevas lógicas y argumentos políticos que llegaban para reemplazarlo o resolver sus dilemas. Sin embargo, sostiene que este proceso se vio truncado por los partidos comunistas que "reprimían toda creatividad intelectual". ${ }^{20}$ Esta tesis es similar a la que esgrime Althusser ${ }^{21}$ para quien la crisis del marxismo (esto es, la necesidad que surgió hacia la década del sesenta de preguntarse por la política, el Estado y las organizaciones de masas al interior de la teoría marxista) tenía, en realidad, profundas raíces que se remontaban a los orígenes mismos del marxismo, pero que, hasta la década del sesenta, había estado bloqueada por el aparato político-ideológico de la ortodoxia marxista. Laclau coincide con esta hipótesis y la radicaliza afirmando que la crisis del marxismo es, en realidad, la crisis de la centralidad de la necesidad histórica frente a la contingencia y que, por ello, fue necesario recurrir a toda una serie de tradiciones intelectuales exteriores a la teoría marxista para poder llevar a cabo una transición al posmarxismo.

Así, fue necesaria la emergencia de un pensamiento contemporáneo ajeno al marxismo para poder desanudar la alianza determinista al interior de la teoría marxista-leninista. De esta manera, junto con el psicoanálisis (para el cual la acción del inconsciente hace ambigua toda significación), con la lingüística estructural (que entendió de una manera renovada el funcionamiento de las identidades relacionales) y con la trasformación del pensamiento filosófico, desde Nietzsche hasta Heidegger, desde el pragmatismo hasta Wittgenstein (que desestabilizaron el esencialismo filosófico) es que Laclau propone reformular el programa materialista de un modo radical en una nueva perspectiva alejada de cualquier determinismo: el posmarxismo.

Así, las tres fuentes del posmarxismo laclausiano son la fenomenología, la filosofía psicoanalítica y las varias corrientes que conforman el posestructuralismo. Según explica, el siglo XX comenzó con tres ilusiones de inmediatez, es decir, de logar un acceso inmediato a las cosas mismas. Estas ilusiones fueron: el referente, el fenómeno y el signo. A su vez, estas tres ilusiones fueron el punto de partida de tres tradiciones: la filosofía analítica, la fenomenología y el estructuralismo. Luego, la historia intelectual de este siglo continuó con la desintegración de estas tradiciones para dar paso a una forma de pensamiento (representada,

\footnotetext{
${ }^{20}$ Laclau y Mouffe, Posmarxismo sin pedido..., p. 136.

${ }^{21}$ Althusser, L. “¡Por fin la crisis del marxismo!” En L. Althusser, La soledad de Maquiavelo, (pp. 283-298). (Madrid: Akal, 2015)
} 
en principio, por Wittgenstein, Heidegger y el posestructuralismo) en la que la mediación discursiva es primaria y constitutiva. ${ }^{22}$

Resumiendo, dado que, desde la lectura laclausiana, tanto en Marx como en la historia intelectual del marxismo coexisten dos posiciones en pugna (una materialista/relacionista y una idealista/determinista/esencialista) el objetivo del posmarxismo es privilegiar el momento de la negatividad y superar los momentos de positividad de lo social inscriptos en la teoría marxista. Este abandono de la posición idealista implica demostrar "el carácter histórico, contingente y construido del ser de los objetos y [...] mostrar que esto depende de la reinserción de este ser en el conjunto de las condiciones relacionales que constituyen la vida de la sociedad como un todo". 23

Justamente, la centralidad que le da a la categoría de discurso resulta de su intento por subrayar el carácter puramente histórico y contingente del ser de los objetos. Para Laclau, el pensamiento contemporáneo en su conjunto (dentro del cual se destacan el giro pragmatista, la crítica antiesencialista de la filosofía psicoanalítica, la crítica a la teoría del signo posestructuralista y las teorías de Wittgenstein y de Heidegger) es un intento por asumir el carácter meramente histórico del ser que, gracias a la proliferación de las dislocaciones generadas por el capitalismo, se torna más visible que antaño; y de apartarse de las posiciones que intentan resolver este problema con salidas esencialistas o deterministas. A esto podemos agregar que su planteo es que la contienda del pensamiento contemporáneo con el esencialismo, el idealismo y el determinismo es también una historia interna del marxismo. Así, su apuesta posmarxista se enrola en la revitalización de la tradición intelectual relacionista y no determinista de lo social inscrita en una parte menor del marxismo y, para esto, retoma los esfuerzos de los pensamientos contemporáneos no marxistas.

Asimismo, según declaran Laclau y Mouffe, el posmarxismo es un esfuerzo persistente por adaptarse a la realidad del mundo contemporáneo, esto es, a las transformaciones capitalistas que alteran constantemente las secuencias discursivas que construyen la realidad, haciendo plenamente visible su contingencia e historicidad. Con esto, se suman a la larga lista de autores coetáneos que afirman que los cambios en el capitalismo contemporáneo no permiten seguir sosteniendo las tesis fundamentales de un Marx nacido en otro capitalismo. Sin embargo, para ellos no tiene sentido abandonar en bloque el marxismo, sino que es preciso, más bien, abordar los problemas políticos de las sociedades posmodernas

\footnotetext{
${ }^{22}$ Laclau, E., "Identidad y hegemonía: el rol de la universalidad en la constitución de lógicas políticas". En: Butler, J., Laclau, E. y Žižek, S., Contingencia, hegemonía, universalidad. Diálogos contemporáneos de izquierda. (Buenos Aires: FCE, 2004) pp. 49-93.

${ }^{23}$ Laclau y Mouffe, Posmarxismo sin pedido..., p 126-127.
} 
rastreando la genealogía del presente y releyendo a Bauer, Luxemburgo, Sorel, Gramsci, Trotsky y Kautsky y extrayendo de ellos sus mejores fragmentos. ${ }^{24}$

En efecto, su apuesta consiste en rescatar de estos autores las categorías en las que priman la negatividad y la opacidad, y en desechar aquellas que apuntan a los determinismos, a la racionalidad, a la positividad y a la transparencia de lo social, como lo serían las de clase social, lucha de clases, capital, comunismo, determinación en última instancia de la economía, entre otras. Por esta razón, por la necesidad de abandonar elementos que han sido centrales en el aparato teórico marxista pero que no permiten pensar la realidad dislocada, plural, relacional del capitalismo contemporáneo, es que sostienen que su apuesta no puede seguir dentro del marxismo, sino que tiene que partir de esta tradición (de su corriente relacionista, de la evidencia de la negatividad y de la opacidad de lo social) para superarla, dejando de lado sus aspectos racionalistas, deterministas y milenaristas.

Según los autores, es necesario ir más allá del horizonte teórico y político del marxismo. Sobre todo, hay que superar el carácter parcial del materialismo de Marx con su dependencia de las categorías de la metafísica tradicional. Al contrario de esto, es la teoría materialista del discurso la que les permite mostrar el mundo como una construcción puramente social que no está fundada en ninguna necesidad externa a ella misma. ${ }^{25}$ En este sentido es que Laclau abandona la categoría de clase pensada como un dato objetivo, necesario y a priori de toda sociedad para pasar a buscar sus condiciones de posibilidad, las cuales son, para él, netamente históricas y contingentes, nunca necesarias.

Este viraje tiene consecuencias también en el modo en el que aborda la cuestión de la historia y la transformación social. Mientras que, según Laclau, el marxismo clásico fija un sentido objetivo de la historia como un horizonte incuestionable, el posmarixmo pretende historizar el horizonte mismo y mostrar su radical contingencia. En definitiva, lo que propone es historizar y relativizar las categorías centrales del marxismo para poder cavilar otras posibilidades históricas diferentes a las pensables dentro del marxismo. ${ }^{26}$ Por su parte, este radical historicismo es uno de los flancos privilegiados de la crítica que le realiza Žižek al pensamiento laclausiano, como veremos más adelante.

Tras el análisis realizado, podemos concluir que la estrategia teórico-discursiva laclausiana parte de una hipótesis de lectura que presupone un Marx escindido en dos posiciones epistemológicas antagónicas (materialismo/idealismo). Luego, articula la posición

\footnotetext{
${ }^{24}$ Laclau, E, Nuevas reflexiones...

${ }^{25}$ Laclau y Mouffe, Posmarxismo sin pedido...

${ }^{26}$ Laclau y Mouffe, Posmarxismo sin pedido...
} 
idealista a los intelectuales de la Segunda Internacional y a la mayor parte de los teóricos marxistas, y esto le da pie para fundar un posmarxismo, esto es, una teoría que si bien parte de esta tradición teórica se aleja de ella al abandonar la mayor parte de sus categorías constitutivas. Esta nueva corriente tiene como objetivo retomar la vertiente materialista, relacionista y contingente de la teoría marxista y enterrar la variante idealista, determinista y esencialista de la misma. Para ello, se nutre de los aportes desarrollados por teorías no marxistas del pensamiento contemporáneo. Es decir, para componer su teoría posmarxista, Laclau define cuidadosamente a su adversario teórico-político: el determinismo y todos los intelectuales y desarrollos marxistas que caen bajo este gran paraguas.

Nuestra hipótesis es que su teoría posmarxista es la formulación de una salida a un problema que él mismo ha formulado en estos términos: la dualidad de Marx, la hegemonía de la vertiente determinista dentro del marxismo y el reconocimiento de los autores que intentaron formular líneas hegemónico-articulatorias. Esta identificación, conceptualización y definición del "determinismo marxista" sobredetermina (aunque no unívocamente) la empresa teórica laclausiana, ya que el desarrollo de su armazón teórico-político está en franca relación de demarcación con estas definiciones. En este sentido, los conceptos centrales del aparato laclausiano (discurso, dislocación, hegemonía, antagonismo, articulación, entre otros) son elementos que intentan desmarcarse de los componentes cardinales de la teoría marxista clásica (para el argentino, de la corriente esencialista al interior de la misma) y que pretenden ubicarse en un territorio posfundacional.

La línea argumental construida por Laclau que aquí hemos desarrollado ha cosechado tanto detractores como partidarios. Hay quienes festejan que haya podido superar el determinismo de clases marxistas con una teoría sólida. Por ejemplo, para Cuevas su teoría de la hegemonía "incorpora una ontología social anti-esencialista y postfundacional, con elementos de la filosofía postestructuralista", gracias a lo cual "rompió definitivamente con el determinismo y el esencialismo de clases del paradigma marxista". 27

Pero también abundan quienes, desde el marxismo, ponen en cuestión la construcción laclausiana de la narrativa de la historia de esta tradición. Para Borón, el adversario contra el que pelea Laclau no es más que una "caricatura del marxismo inspirada en las aberraciones del marxismo-leninismo perpetradas por el stalinismo". ${ }^{28}$ Es decir, para él, la definición que realiza del marxismo es una reducción de su inmensa historia intelectual a su versión

\footnotetext{
${ }^{27}$ Cuevas, H., "Introducción. Obra e historia intelectual de Ernesto Laclau”, Revista Pléyade 16 (2015), pp. 9-19.

${ }^{28}$ Borón, A. “¿Posmarxismo? Crisis, recomposición o liquidación del marxismo en la obra de Ernesto Laclau." Revista de Ciencias Sociales, 6 (1999): 1-41.
} 
estalinista. Según postula, Laclau se auto-diseña un enemigo débil (basado en las peores deformaciones y vulgatas del marxismo) para proceder luego a declarar heroicamente que quiere destruirlo. Para Borón, este posmarxismo, lejos de ser una superación de la teoría marxista, implica un salto hacia atrás, hacia un idealismo hegeliano. ${ }^{29}$ De hecho, continúa, no es más que una teoría posmoderna en la que lo que prima es lo político y que soslaya "la estructura y la dinámica del capitalismo y sus tendencias hacia la concentración monopólica de la riqueza y el poder, la superxplotación de las masas populares, la postergación de las regiones periféricas y la destrucción del medioambiente". ${ }^{30}$ En esta misma línea crítica podemos encontrar a Slavoj Žižek, como veremos enseguida.

Laclau se defiende de sus críticos afirmando que su pensamiento no opera un abandono del marxismo sino, más bien, una deconstrucción del mismo. A este respecto, argumenta que si bien siempre se piensa desde una tradición, esto no significa que la relación con ésta sea de sumisión y repetición de sus dogmas, sino que debe ser de transformación y crítica: "Uno debe construir su propio discurso como diferencia en relación con esta tradición y esto implica a la vez continuidades y discontinuidades". ${ }^{31}$ Para él, no tiene sentido continuar bajo una tradición que no permite la creatividad ni la inscripción de nuevos problemas. Justamente, las teorías deben adaptarse a las nuevas realidades que se van constituyendo.

En este sentido, sostenemos que Laclau somete a la teoría marxista al historicismo del que es partidario puesto que la operación que realiza es bañar de carácter histórico y transitorio a esta tradición y adaptar el instrumental teórico posmarxista a los cambios históricos acontecidos en el capitalismo contemporáneo. Según él mismo arguye, el marxismo debe entenderse simplemente como un momento "histórico, parcial y limitado dentro de una línea histórica más amplia, que es la tradición de transformación radical de Occidente".32 Justamente, su posmarxismo se posiciona como una nueva tradición que parte del marxismo pero que se compromete en restaurar su relación con el presente y con su historicidad. ${ }^{33}$

\section{Žižek y su crítica a la intelectualidad posmoderna}

"En el siglo XV, cuando Rusia estaba ocupada por los mongoles, un campesino y su mujer estaban andando por un polvoriento camino; un guerrero mongol a

\footnotetext{
${ }^{29}$ Borón, A, “¿Posmarxismo? Crisis,...”

${ }^{30}$ Borón, A, “¿Posmarxismo? Crisis,...”, p. 33.

${ }^{31}$ Laclau, Nuevas reflexiones..., p. 189.

${ }^{32}$ Laclau, Nuevas reflexiones..., p. 189.

${ }^{33}$ Laclau, Nuevas reflexiones...
} 
caballo se detiene a su lado y le dice al campesino que va a violar a su mujer; a continuación, añade: «Pero, como hay mucho polvo en el suelo, debes sujetar mis testículos mientras violo a tu mujer, de manera que no se ensucien». Una vez que el mongol ha realizado la acción y se aleja cabalgando, el campesino empieza a reírse y a dar saltos de alegría. Su sorprendida mujer le pregunta: « ¿Cómo puedes estar dando saltos de alegría, cuando he sido brutalmente violada en tu presencia?». El agricultor responde: « ¡Pero le he fastidiado! ¡Tiene los cojones llenos de polvo!». [...]¿No está la actual izquierda crítica en la misma posición? (entre los nombres contemporáneos para desprestigiar con más ligereza que nunca a aquellos en el poder, podríamos incluir la «deconstrucción»o la «protección de las libertades individuales»)" ".34

El punto de largada de Žižek, a contramano de Laclau, no es una crítica al marxismo clásico o a la teoría marxista en su conjunto, sino que apunta sus misiles hacia lo que él llama, de manera amplia, la intelectualidad posmoderna. Para el esloveno, el peligro más grande para las luchas emancipatorias actuales proviene de un conjunto de intelectuales contemporáneos que se presentan como renovadores del pensamiento de izquierda pero que lejos están de serlo. Estos serían los herederos del movimiento de Mayo de 1968, una generación que, según sostiene, abandonó como horizonte la militancia por un cambio social global y puso en primer plano las luchas por la identidad y la transformación de la subjetividad. ${ }^{35}$ Para él, los principios aparentemente radicales de esta izquierda posmoderna han sido deglutidos e incorporados por el capitalismo, por lo que sus intelectuales han terminado siendo cómplices necesarios de la dominación capitalista de los últimos decenios.

Según él mismo dice, el punto de partida de su empresa teórica es "las (im)posibilidades de un pensamiento político radical y de una práctica política radical en el momento actual". ${ }^{36}$ Esa es su principal preocupación y de aquí derivan sus continuos ataques y críticas al frente posestructuralista y a la izquierda contemporánea, agentes que no se habrían comprometido con una alternativa global, sino que se han decantado por una tibia resignación.

\footnotetext{
34 Žižek, S., Primero como tragedia, después como farsa. (Madrid: Akal, 2011), p. 6-7.

${ }^{35}$ En esto Žižek sigue la línea de Lacan quien fuera muy crítico de los movimientos de Mayo de 1968. En una nota al diario El País, comenta que en aquella ocasión el psicoanalista francés vociferó contra los manifestantes: "como revolucionarios, sois unos histéricos en busca de un nuevo amo. Y lo tendréis". En: https://elpais.com/diario/2008/05/01/opinion/1209592812_850215.html.

36 Žižek, S. “¿Lucha de clases o posmodernismo? ¡Sí, por favor!” En: Butler, J., Laclau, E. y Žižek, S., Contingencia, hegemonía, universalidad. Diálogos contemporáneos de izquierda. (Buenos Aires: FCE, 2004), pp. 95-140.
} 
En el amplio saco de intelectuales posmodernos podemos encontrar a los teóricos del posestructuralismo francés y sus herederos, dentro de los cuales Žižek localiza a Ernesto Laclau $^{37}$. En este sentido, podríamos decir que uno de los componentes principales del frente de batalla del corpus žižekiano está ubicado en la academia contemporánea, el lugar en donde era furor, hace algunas décadas, la moda post (postestructuralista, postpolítica, posmoderna, postideológica). Según Roggerone:

Era en la academia donde la perspectiva de los estudios culturales rechazaba al marxismo como una filosofía esencialista, fundamentalista y económicamente reduccionista; era en la academia donde se proponía reemplazar la política clasista por una política identitaria y multiculturalista mediante la cual se aspiraba al reconocimiento; era en la academia donde, acudiendo a pensadores tan disímiles como Jürgen Habermas o Jacques Derrida, resultaba verdaderamente "más fácil imaginar el 'fin del mundo' que un cambio mucho más modesto en el modo de producción". 38

En este sentido, sostenemos que Žižek irrumpe allí para ir a contramano de las tradiciones intelectuales que se estaban instalando en aquel ámbito. Para él, las distintas corrientes montadas en la academia, por más contrarias que se digan entre sí, tienen algo en común: el presupuesto político de que nada puede cambiar realmente. Así se interroga:

¿Qué pasa si, pese a los grandes debates públicos apasionados entre deconstructivistas, pragmáticos, habermasianos y cognitivistas, comparten no obstante una serie de premisas filosóficas? ¿Qué pasa si hay una proximidad no reconocida entre ellos? ¿Y qué pasa si la tarea de hoy es precisamente romper con este terreno de premisas compartidas $?^{39}$

$\mathrm{Su}$ objetivo, entonces, es romper con estas corrientes. De alguna manera, las diversas y demoledoras críticas que dirige a los pensamientos teórico-políticos posmodernos son una de las principales armas para atacar las resistencias ideológicas e intelectuales al cambio radical.

\footnotetext{
${ }^{37}$ Recordemos que Žižek conoció a Laclau en Europa en la década del ochenta y se sumó, de manera entusiasta, a su propuesta de democracia radical apoyando muchas de sus formulaciones teóricas. Sin embargo, en la medida en que iba madurando su teoría política (de los 2000 en adelante), se iba tejiendo, entre ellos, una verdadera polémica en la que las diferencias fueron in crescendo hasta el acto final, cuando los contendientes decidieron ponerle fin a sus referencias cruzadas, al menos las explícitas. En ese proceso, Žižek se volcó, finalmente, por una posición comunista y se convirtió en un fuerte crítico tanto del proyecto de democracia radical laclausiano y como de su teoría populista.

38 Roggerone, S. (2015) "Lo saben, pero lo hacen. Slavoj Žižek y la persistencia de la crítica de la ideología." Pilquen, Sección Ciencias Sociales, Vol. 18, N 3, (2015), p. 5.

39 Žižek, S. “¿Lucha de clases...”, p. 140.
} 
Otra lectura posible sobre el adversario teórico-político žižekiano es la hipótesis que presenta Castro-Gómez. ${ }^{40}$ Para él, éste es un cónclave compuesto por tres elementos: a nivel ideológico, por el ideario que emergió en las movilizaciones de Mayo de 1968; a nivel teórico, por los filósofos posestructuralistas como Foucault, Deleuze y Derrida, entre otros; y a nivel de práctica política, por los llamados nuevos movimientos sociales que proliferaron a lo largo y ancho del globo hacia mediados de la década del sesenta. Estos tres elementos son los que conforman esa izquierda posmoderna cuyos herederos y blanco de los ataques del esloveno son: el posestructuralismo y sus derivas, los estudios culturales, las teorías poscoloniales, algunos feminismos y, cómo no, el posmarxismo laclausiano. Nuestra hipótesis es que es a partir de las críticas a estas posiciones (aunque no únicamente) que Žižek edifica una propuesta teórico-política que se centra en recuperar varios de los elementos olvidados por el pensamiento posmoderno como las nociones de sujeto trascendental, clase, proletariado, comunismo, economía, entre otros.

Como decíamos, la conjetura que sostiene el pensador oriundo de Liubliana es que el ideario de las revueltas anticapitalistas de 1968 fue reabsorbido por un capitalismo que ahora se presenta con rostro humano. La paradoja que plantea es que si bien estas protestas eran activas y politizadas, ese espíritu se trasladó a una pseudoactividad despolitizada (comprar un producto eco, donar con una compra a una causa social, tener nuevos estilos de vida saludables o sustentables, etc.), es decir, a una total pasividad social. ${ }^{41}$ Asimismo, para Žižek estos efectos son, también, consecuencia del agotamiento del potencial emancipatorio del ideario de Mayo de 1968. A partir de mediados de los setenta, este agotamiento se vivió, para él, como "un passage a l'acte que asumió tres formas principales: la búsqueda de formas extremas de jouissance sexual; el terrorismo político izquierdista [...]; y, finalmente, el giro hacia lo Real de una experiencia interior (misticismo oriental)". ${ }^{2}$

Ahora bien, el movimiento de Mayo de 1968 también sembró efectos en la academia. Uno de ellos es la especial atención que se comenzó a prestar a los llamados "frentes secundarios", en oposición la lucha proletaria liderada por los partidos comunistas tradicionales significada como "frente principal". Una de las críticas cardinales que les refrenda el filósofo esloveno a los intelectuales posmodernos es que, en su afán de centrar su atención en estas nuevas luchas, han contribuido enormemente a la despolitización de la economía, sin caer en la cuenta de que existe un horizonte capitalista que hace posible y

\footnotetext{
${ }^{40}$ Castro-Gómez, S., Revoluciones sin sujeto. Slavoj Žižek y la crítica del historicismo posmoderno (México: Akal, 2015)

${ }^{41}$ Žižek, C, Primero como tragedia...

${ }^{42}$ Žižek, C, Primero como tragedia ..., p. 39.
} 
estructura todas estas luchas por la subjetividad o el reconocimiento. Según nos dice, el problema de la política multiculturalista progresista actual es que suspende la dimensión global del capitalismo y, en cambio, se limita a estudiar el modo en el que el capitalismo alimenta opresiones particulares de raza, de sexo, etc. Para él, el capitalismo es, más bien, el telón de fondo y el terreno mismo para la emergencia de estas subjetividades políticas múltiples tan extendidas. ${ }^{43}$

De este modo, la contradicción que presenta Žižek es que si bien el posmodernismo politiza un cúmulo de ámbitos nuevos, lo hace despolitizando, a su vez, al capitalismo y a la economía. ${ }^{44}$ Según su mirada, hay una suerte de autoengaño por parte de la política posmoderna de múltiples identidades, puesto que esta corriente festeja la multiplicación de identidades políticas mientras "presupone calladamente un sistema "naturalizado" no tematizado de relaciones económicas". 45

Así, nos dice, si bien es cierto que la irreductible pluralidad de luchas posmodernas describe un proceso histórico real, ninguno de los teóricos posmodernos asume la resignación que implica la aceptación del capitalismo como única opción posible. Según su perspectiva, junto con la aceptación de la pluralidad de antagonismos sociales en el capitalismo contemporáneo viene "la renuncia a todo intento real de superar el régimen capitalista liberal existente". ${ }^{46}$ Para argumentar esto se apoya en la idea de que la política de la identidad se sostiene, en parte, a través de una cierta renaturalización del capitalismo. ${ }^{47}$

Estas críticas a la visión posmoderna de los movimientos sociales contemporáneos tienen efectos en su formulación teórica puesto que, a diferencia de Laclau, para Žižek estas luchas no son iguales o, dicho de otro modo, no son todas meros particulares articulables contingentemente. Para él, en la serie de luchas particulares hay siempre una que, aunque parezca funcionar como parte de la serie, provee el horizonte de la misma como tal. Así, se puede aplicar aquí la enseñanza de la dialéctica hegeliana de la universalidad concreta en la cual “en la relación entre un genus y su subespecie, una de éstas siempre será el elemento que niega el rasgo universal mismo del genus". ${ }^{48}$ Luego, en base a esta idea, el esloveno repone el axioma marxista de que existe una lucha (la proletaria en sentido amplio) que sobredetermina al resto de luchas particulares que se dan al interior del capitalismo.

\footnotetext{
43 Žižek, S. “¿Lucha de clases...”.

44 Žižek, S. “¿Lucha de clases...”.

45 Žižek, S. “¿Lucha de clases...”, p. 117.

46 Žižek, S. “¿Lucha de clases...”, p. 101.

47 Žižek, S. "¿Lucha de clases...”,

${ }^{48}$ Žižek, S. “¿Lucha de clases...”, p. 107
} 
Pero continuemos con su embate contra el pensamiento posmoderno. Otra de las críticas que le efectúa Žižek es su radical historicismo, esto es, la tendencia a explicar todos los fenómenos políticos y sociales recurriendo a la historia y reduciéndolos a las relaciones históricas de poder que les han dado origen. A este historicismo posmoderno le reprocha, sobre todo, que la historia sea el único escenario donde se desarrollan las relaciones sociales. $\mathrm{Su}$ propuesta teórico-política, en cambio, se preocupa por subir a la escena las condiciones ontológicas de la experiencia humana, es decir, la estructura trascendental del sujeto que no tiene historia ni puede reducirse a ella. Como bien explica Castro-Gómez:

Žižek dirá que el sujeto no se reduce jamás a los procesos históricos de subjetivación. Siempre queda un resto, un “exceso" de sujeto que no podrá ser subjetivado y que "retorna" siempre (como lo Real de Lacan) para evidenciar el impasse de todos nuestros proyectos emancipatorios.$^{49}$

Para Žižek, el historicismo es la forma ideológica del capitalismo posmoderno. ${ }^{50}$ En este sentido, el problema con esta corriente es que, en su afán por centrarse en los procesos de subjetivación particulares, renuncia a la universalización de intereses que, para él, es el gesto político por excelencia. Como resultado, la fórmula posmoderna termina, para nuestro autor, por caer en un relativismo que le impide formular un horizonte emancipatorio global. Al contrario, queda presa del mito de Fukuyama del fin de la historia, al aceptar que no hay escapatoria al capitalismo liberal-democrático, sino que lo único que queda es lograr que sea un poco más justo y más tolerante. Así, la apuesta teórico-política žižekiana se centra en reponer una serie de supuestos que recurren a una ontología del sujeto trascendental.

Como consecuencia de todo esto, podríamos decir que su principal crítica propinada a la izquierda posmoderna contemporánea es que no es capaz de ofrecer una alternativa global viable porque ha caído presa del mito ideológico por excelencia del capitalismo: que él es el único sistema de vida posible, o al menos, el mal menor. Es decir, afirma que la izquierda no se inclina por una alternativa factible al capitalismo, sino que ha quedado atrapada en su fantasía ideológica: como no hay alternativa, solo queda luchar por mejorar mínimamente lo que hay. Se trata de una política de la resignación que no tiene nada de radical. Dicho de otro modo, para el esloveno, la izquierda se ha sometido al chantaje de la ideología capitalista.

Para él, el elogio a la proliferación de nuevas subjetividades políticas, la muerte de toda fijación esencialista y la aserción de la contingencia plena de lo social se producen sobre el fondo de cierta renuncia a la idea de un cambio global en las relaciones fundamentales de

\footnotetext{
${ }^{49}$ Castro Gómez, Revoluciones sin sujeto..., p. 7

50 Žižek, C, Primero como tragedia...
} 
nuestra sociedad y de una aceptación silenciosa del marco capitalista democrático-liberal. Este sistema, afirma, no es otra cosa que el telón de fondo incuestionable de las políticas de la identidad. $^{51}$ En sus palabras, la izquierda debe tomar una decisión planteada en estos términos: La izquierda tiene hoy una opción: o acepta el horizonte democrático liberal predominante (democracia, derechos humanos y libertades...), y emprende una batalla hegemónica dentro de él, o arriesga el gesto opuesto de rechazar sus términos mismos, de rechazar directamente el chantaje liberal actual de que propiciar cualquier perspectiva de cambio radical allana el camino al totalitarismo. ${ }^{52}$

Otro de los rasgos de la intelectualidad posmoderna que resulta problemático para el esloveno es su "corrección política" permanente, que tiene como corolario una especie de pánico a la politización en sí. ${ }^{53}$ Para él, su rechazo a albergar cualquier forma de pensamiento que se salga de las coordenadas pospolíticas establecidas no permite pensar y solo deviene, nos dice, en una izquierda de pura protesta sin un programa de cambio viable y global. ${ }^{54} \mathrm{Un}$ ejemplo de esto, señala, es su reacción al populismo racista de derecha en Europa. Cuando éstos se oponen a la inmigración porque quitan puestos de trabajo, la izquierda en vez de reparar en que se trata de un desplazamiento de la lucha de clases (dado que la inmigración es parte de la estrategia del capital para pagar obreros precarizados, para bajar el sueldo de los obreros locales, etc.) contesta con consignas de apertura cultural. Con esto, señala, la izquierda borra el contenido de clase desplazado en esta disputa y, paradójicamente, su inclinación por una posición tolerante, liberal, “constituye la forma más pérfida de la lucha de clases antiproletaria". 55

Retomando el chiste del mongol que referíamos al principio, para Žižek, el problema de la izquierda es que hace mucho ruido y pocas nueces, es decir, cree que está empolvando al violador cuando en realidad solo está emprendiendo un movimiento vano contra el verdadero problema: la violación al pueblo. Siguiendo con la referencia al chiste nos dice: "nuestra Tesis 11 debe ser: en nuestras sociedades, los izquierdistas críticos hasta ahora sólo han conseguido ensuciar a los que están en el poder, cuando de lo que se trata es de castrarlos...".56

Para llevar adelante una "verdadera castración”, Žižek propone animarse al abismo del acto. Para él, la izquierda se maneja bajo las coordenadas de la derecha y del capitalismo, y no

\footnotetext{
51 Žižek, S. "Mantener el lugar”. En: Butler, J., Laclau, E. y Žižek, S., Contingencia, hegemonía, universalidad. Diálogos contemporáneos de izquierda. (Buenos Aires: FCE, 2004) pp. 307-328.

52 Žižek, S. "Mantener el lugar"... p. 327.

53 Žižek, S. Contra la tentación populista. (Buenos Aires: Ediciones Godot, 2019).

54 Žižek, S. Contra la tentación populista, p. 20.

55 Žižek, S. En defensa de las causas perdidas. (Madrid: Akal, 2011), p. 274

${ }^{56}$ Žižek, S., Primero como tragedia..., p. 7.
} 
emprende el acto auténtico de hacer lo imposible, de promover proyectos políticos que apunten seriamente a cambiar el orden existente y que no se resignen al mismo. Su problema es que se deja chantajear, puesto que cada vez que propone proyectos políticos transformadores se la corre por derecha con la posibilidad de que se trate de un nuevo gulag $\mathrm{u}$ holocausto. En definitiva, sostiene que la izquierda debe comenzar por plantear con firmeza y bajo sus propios términos su proyecto político transformador. ${ }^{57}$

Concatenado con esto, la crítica más importante que Žižek dirige contra el posmodernismo es su reformismo. Su problema, apunta, es que no cuestiona los principios fundamentales de la economía capitalista de mercado ni el régimen político democráticoliberal, sino que ambos son dados por sentado como si no existiera posibilidad de un régimen económico y político diferente. Al contrario de esto, todos los cambios que la izquierda posmoderna propone son dentro del régimen político-económico existente. Así, termina sometida a las premisas de la derecha, por lo que su posición acaba siendo más bien defensiva que propositiva. Su misión sería, por lo menos, formular y defender su propia agenda con más firmeza.

Esto mismo le critica a Laclau puesto que éste plantea articulaciones contingentes y construcción de hegemonía pero siempre sin salirse del marco del régimen liberaldemocrático actual. Claramente, el argentino no coincide con esta idea y defiende su posición contraatacando: por lo menos él, dice, plantea un sistema posible mientras que Žižek no es claro en cuanto al tipo de alternativa que propone. ${ }^{58}$ Además, agrega que la parcialidad del horizonte hegemónico no implica ningún tipo de resignación, sino que todo depende de la lucha y las articulaciones que pueden darse. Es decir, la investidura de un objeto parcial como totalidad social puede implicar tanto un cambio radical como transformaciones menos globales. ${ }^{59}$ El punto es que para Laclau el final está siempre abierto, en cambio, Žižek asimila la parcialidad de las demandas con reformismo o gradualismo.

En este punto, consideramos que Laclau es claro al explicar que su posición no es gradualista, sino que parte de una definición de la política que implica articulaciones y procesos de representación que pueden tomar distintas derivas, ya sea un cambio global o no. Sin embargo, también hay que señalar que la constitución populista es siempre, para Laclau, una constitución estatal y que, en este sentido, su enfoque no es anti-institucionalista. El populismo laclausiano no plantea una revolución redentora, sino una realización histórica

\footnotetext{
57 Žižek, S., “¿La lucha de clases...”

${ }^{58}$ Laclau, E. "Estructura, historia y lo político". En: Butler, J., Laclau, E. y Žižek, S., Contingencia, hegemonía, universalidad. Diálogos contemporáneos de izquierda. (Buenos Aires: FCE, 2004), p. 197-200.

${ }^{59}$ Laclau, E., La razón populista (Buenos Aires: FCE, 2005), p. 292.
} 
signada por una ética de lo posible. En cambio, el acto revolucionario žižekiano está signado por una ética de lo imposible y por una priorización de las luchas anti-capitalistas frente a las demás (una distinción inadmisible para Laclau).

Resumiendo lo dicho hasta aquí, para Žižek la eficacia de la ideología capitalista radica en haber podido asociar determinadas demandas progresistas que comenzaron con los movimientos de Mayo de 1968 con el modelo capitalista como mejor instrumento para realizarlas. El caso del ecocapitalismo reinante es un claro ejemplo. Según asevera, la versión ideológica que se ha vuelto hegemónica es la de un capitalismo socialmente responsable. Este enfoque ya no opone mercado y responsabilidad social, ya que ambos pueden aliarse en pos de un beneficio mutuo. Así, el capitalismo, con sus empresas que no solo producen beneficios económicos, sino también ambientales, sociales, comunitarios, etc., se presenta al mundo como el instrumento más eficaz para consumar el bien común. ${ }^{60}$ Éste es, para Žižek, el gran mito del capitalismo contemporáneo, dentro del cual muchas de las teorías y corrientes políticas que se declaran radicales han caído.

Así, la estrategia teórico-discursiva de Žižek parte de una premisa y es que el pensamiento político crítico actual no se la juega por una apuesta por una alternativa global radical viable. Los paladines de esta política de la resignación son, para él, todos estos intelectuales posmodernos que han copado la academia y la izquierda contemporánea, y cuyos planteos no hacen más que demostrar que han caído en el chantaje ideológico del capitalismo: las opciones son aceptar el capitalismo tal cual es o hacerlo un poco más justo. Según su postura, se trata de una falsa dicotomía a la que hay que responder con una negativa a elegir. ${ }^{61}$ Lo paradojal es que, luego de este perfilado del posmodernismo, se vuelca por reponer algunas de las categorías nucleares del marxismo clásico como las de clase, proletariado, economía como telón de fondo de las luchas sociales, comunismo, entre otras. Categorías que el pensamiento posmoderno ha decidido abandonar como en el caso de Laclau.

\section{Conclusiones}

A lo largo de estas líneas fuimos perfilando las estrategias teórico-discursivas de construcción de los adversarios teórico-políticos de dos de los representantes más relevantes

\footnotetext{
${ }^{60}$ Žižek, S., Primero como tragedia...

${ }^{61}$ En Contingencia, hegemonía, universalidad, específicamente en el capítulo denominado “¿Lucha de clases o posmodernismo? ¡Sí, por favor!”, Žižek hace referencia a un chiste de los hermanos Groucho Marx en el que ante la convencional pregunta “¿Té o café?” se responde “¡Sí, por favor!”, es decir, con una negativa a elegir. Para él, esto es exactamente lo que hay que hacer frente a la falsa dicotomía que nos presenta la fantasía ideológica del capitalismo: ¿capitalismo tal cual lo conocemos o capitalismo con rostro humano? El desafío es poder pensar una alternativa radical global a esta falsa obligación a elegir.
} 
del amplio campo de los nuevos pensamientos críticos. El foco puesto en este perfilado se forjó con la intención de resaltar a quiénes suben al ring al momento de construir sus teorías, de quiénes se desmarcan, contra quiénes batallan. Como sabemos, las teorías no se producen en el vacío, sino que lo hacen en franca oposición a otras posiciones, en diálogo/disputa con otros desarrollos. Y estos posicionamientos teórico-políticos en el campo en el que se insertan surcan, aunque no unívocamente, sus desarrollos, sus elecciones conceptuales, en definitiva, sus construcciones teóricas. De esta manera, el argumento que intentamos sostener en estas páginas es que Laclau y Žižek emprenden caminos de magnitud inversamente proporcional. Mientras que Laclau parte de la historia intelectual del marxismo, abandona sus categorías cardinales y funda un posmarxismo; Žižek, que no viene de la tradición creada por Marx, critica a la intelectualidad posmoderna y construye una teoría política basada en sus categorías más fundamentales.

En el caso de Laclau, pudimos ver que su narrativa parte de la hipótesis de un Marx escindido y de una tradición desarrollada en su nombre que conservó el dualismo entre materialismo relacional y determinismo esencialista. Esta construcción tiene como efecto en Laclau la necesidad de fundar una nueva tradición que si bien parte del marxismo se aleja de él y de sus categorías centrales y, busca, en cambio, la edificación de conceptos en los que destaque el relacionismo radical y la contingencia. Así, para Laclau, la historia del marxismo es la historia de esta puja entre determinismo y relacionismo, y su estrategia apunta a articular el determinismo a los intelectuales de la II Internacional; al tiempo que se inmiscuye en el pensamiento contemporáneo para buscar allí los elementos necesarios para la cimentación del posmarxismo. De esta manera, su teoría se configura como la respuesta a un problema que él ha definido en ciertos términos.

Sin embargo, podemos preguntarnos si, en su afán de diferenciarse de la teoría marxista clásica, no termina por caricaturizar en extremo al marxismo del que se diferencia. En este sentido, coincidimos con la visión de Borón acerca de que, al fin y al cabo, el marxismo laclausiano termina representado por su versión más tosca y vulgar que es el de la II Internacional. Creemos que al interior de la teoría marxista en grande hay muchos elementos teóricos para pensar lo social de manera relacional y no reduccionista. Asimismo, dudamos de si la manera de pensar la política en la contemporaneidad exige salir del campo problemático marxista y superarlo, puesto que muchos de los conceptos de esta tradición no envejecen y siguen teniendo vigencia para pensar la actualidad de un capitalismo que continúa mercantilizando cada vez más esferas de la vida. 
Por su parte, pudimos ver que la estrategia žižekiana toma como punto de partida la evidencia de la falta de una propuesta global transformadora en el pensamiento radical posmoderno. Así, nuestro autor le dirige diversas críticas al posmodernismo como su aceptación del capitalismo liberal-democrático, su reformismo, su historicismo, su corrección política, entre otras, para terminar afirmando que su problema principal es que ha caído preso del chantaje impuesto por la fantasía ideológica capitalista. De esta manera, su propuesta teórica parte de esta certidumbre y toma derivas impensadas, sobre todo teniendo en cuenta que apoyó, por un tiempo, el proyecto de democracia radical de Laclau y Mouffe. Así, el efecto imprevisto de la polémica que instala el esloveno al interior del pensamiento contemporáneo es que viniendo desde las afueras del marxismo termina reponiendo algunas de sus categorías troncales y abandonadas por los dispositivos teóricos posmodernos.

En este punto, si bien concedemos que muchas de las críticas que Žižek le propina al pensamiento de izquierda contemporáneo son acertadas, en tanto mueven el avispero al obligar a reflexionar sobre la posición de la izquierda frente a la agenda de la derecha y sobre las posibilidades de un horizonte emancipatorio en las condiciones actuales, nos interrogarnos si, en su afán de criticar a la intelectualidad posmoderna, no termina por hacer un movimiento exagerado al reponer algunas categorías nucleares del marxismo pero, justamente, en su versión determinista. 